\title{
The impact of plant-derived flavonoids on mood, memory and motorskills in healthy older UK adults
}

\author{
Pauline S. How ${ }^{1}$, Judi A. Ellis ${ }^{1}$, Sara Neshatdoust ${ }^{2}$ and Jeremy P. E. Spencer ${ }^{2}$ \\ ${ }^{1}$ School of Psychology and Clinical Language Sciences, University of Reading, Reading RG6 6AL, UK and ${ }^{2}$ School of \\ Chemistry, Food Biosciences and Pharmacy, University of Reading, Reading RG6 6AP, UK
}

Dietary interventions may have the potential to ameliorate cognitive changes, e.g. those preceding a diagnosis of Alzheimer's Disease (AD). Cognitive changes are part of normal healthy ageing, but in $\mathrm{AD}$ the rate of change is more rapid than that considered to be in the normal range. The initial amnesic stage of $\mathrm{AD}$ is often followed by impairments in attention; indeed, these attentional difficulties may appear earlier than suggested by current research ${ }^{(1)}$. Animal research has shown significant improvements in spatial working memory after 8 weeks of supplementation with a flavonoid-rich blueberry (Vaccinium spp.) $\operatorname{diet}^{(2)}$.

The present study followed on from an acute intervention trial carried out with young adults (18-30 years) ${ }^{(3)}$. A key finding from this first investigation into the effects of flavonoid-rich blueberries on cognitive function was an improvement in attention in the absence of reaction-time changes. Using a randomised double-blind placebo-controlled cross-over design an acute intervention trial was carried out with older adults (Selected from Ageing Panel - healthy adults; 60-78 years; MMSE score $>/=24^{(4)}$ ) using a single acute supplementation of blueberry ( $200 \mathrm{~g}$ blueberries in $150 \mathrm{ml}$ milk) or a placebo control. The effects on mood, memory, executive function and motor skills were measured before the drink and $1 \mathrm{~h}$ and $5 \mathrm{~h}$ following consumption, and were assessed as previously described ${ }^{(5)}$.

There was a trend for improvement in sustained attention $5 \mathrm{~h}$ after the blueberry drink compared with a decline in attention $5 \mathrm{~h}$ following the placebo (see Figure). The difference in the mean number of correctly-detected targets on the 'go-nogo' task ${ }^{(5)}$ (a measure of the executive function of attention) compared between the blueberry drink and the placebo, $5 \mathrm{~h}$ after the drink, was marginally significant $(P=0.08 ; n 16)$. Motor performance improved over time $(P=0.003)$, irrespective of the type of drink, but no significant improvements in performance were found on measures of spatial and working memory $(P>0.05)$.

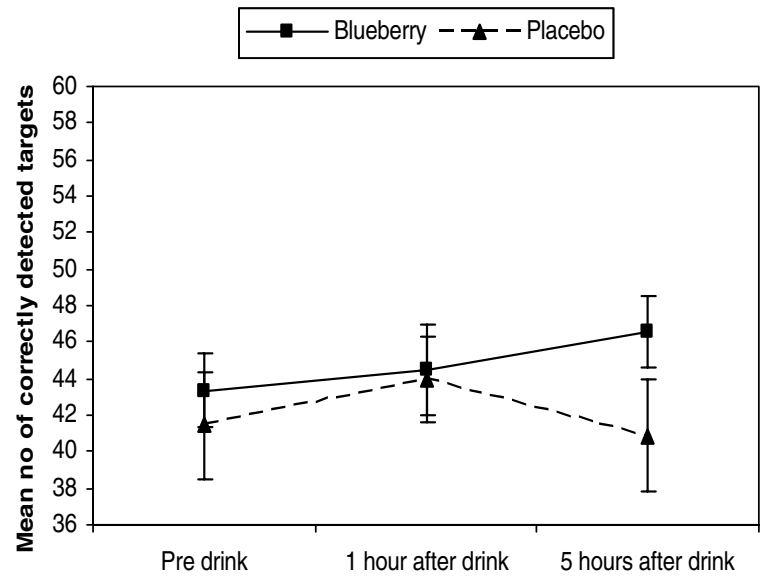

Acute supplementation of healthy older individuals with blueberry showed a tendency to selectively improve sustained attention rather than global cognitive function. This finding replicates the trend found with the healthy young individuals. The mechanism by which this improvement is affected is not known but an enhancement of the neural circuitry responsible for sustained attention, located in the right prefrontal and parietal lobes of the brain, by flavonoids present in blueberry may be responsible ${ }^{(6)}$. An assessment of performance of healthy older individuals on other aspects of executive function, following chronic supplementation, has commenced.

1. Reisberg B, Prichep L, Mosconi L et al. (2008) Alzheimer's Dement 4, S98-S108.

2. Williams CM, Abd El Mohsen M, Vauzour D, Butler LT, Ellis JA, Whiteman M \& Spencer JPE (2008) Free Radic Biol Med 45, $295-305$.

3. How PS, Cox R, Ellis JA \& Spencer JPE (2007) Proc Nutr Soc 66, 87A.

4. Folstein MF, Folstein SE \& McHugh PR (1975) J Psychiatr Res 12, 189-198.

5. Garavan H, Ross TJ \& Stein EA (1999) Proc Natl Acad Sci USA 96, 8301-8306.

6. Coull JT, Frackowiak RSJ \& Frith CD (1998) Neuropsychologia 36, 1325-1334. 